Associate Professor, Candidate of Philosophycal Science, Assistant professor Department of History and Philosophy, State Maritime University Admiral Ushakov, Russia, grape3@yandex.ru
p-ISSN: 2308-4944 (print) e-ISSN: 2409-0085 (online)

Year: $2016 \quad$ Issue: 3 Volume: 35

Published: $30.03 .2016 \quad$ http://T-Science.org

SECTION 30. Philosophy.

\title{
THE PROBLEM OF HUMAN RIGHTS AND FREEDOM OF THE PERSON IN THE WORKS OF S. L. FRANK AND MODERN
}

\begin{abstract}
This article discusses one of the most pressing problems of human existence: the problem of the individual, his rights and freedoms as the bearer and creator of spiritual values, the implementation of which in the socio-historical life, according to Frank's, forms the content of the entire culture.

Key words: identity, freedom, right, moral unacceptability of economic exploitation.

Language: Russian

Citation: Vinogradova EV (2016) THE PROBLEM OF HUMAN RIGHTS AND FREEDOM OF THE PERSON IN THE WORKS OF S. L. FRANK AND MODERN. ISJ Theoretical \& Applied Science, 03 (35): 126131.

Soi: http://s-o-i.org/1.1/TAS-03-35-21 Doi: crossef http://dx.doi.org/10.15863/TAS.2016.03.35.21

УДК 1:3+930.1

ПРОБЛЕМА ПРАВ И СВОБОДЫ ЛИЧНОСТИ В ТВОРЧЕСТВЕ С. Л. ФРАНКА И СОВРЕМЕННОСТЬ

Аннотация: В статье рассматривается одна из самых актуальных проблем существования человечества: проблема личности, ее правах и свободах как носителя и твориа духовных ценностей, осуществление которых в общественно-исторической жизни, по мнению С. Л. Франка, образует содержание всей культуры.
\end{abstract}

Ключевые слова: личность, свобода, право, моральная недопустимость хозяйственной эксплуатации.

Семен Людвигович Франк - один из ярких и самобытных философов Русского Ренессанса. С. Л. Франк родился 16(29) января 1877 г. в Москве в интеллигентной семье. Его отец - Людвиг Семенович - врач, за заслуги перед Россией в годы русско-турецкой войны. 1877-78 гг. получил дворянский титул. С. Л. Франк после окончания гимназии поступил в Московский университет на юридический факультет, а завершает образование в Казанском университете. (Связано это с его политической неблагонадежностью - участвовал в студенческом движении). После этого начинается его творческая и преподавательская деятельность. В 1922 г. вместе с большой группой видных ученых, писателей, философов был выслан из России на небезызвестном «философском пароходе» вместе с семьей и поселился в Берлине. Начался долгий, трудный, но плодотворный период его жизни. Вдали от Родины он пишет самые значительные свои работы: «Крушение кумиров» (1924), «Смысл жизни» (1926), «Духовные основы общества» (1939), «Непостижимое» (1939) и др.

Творчество С. Л. Франка многогранно. Круг его профессиональных интересов широк. Это онтология, гносеология, проблемы общественной жизни, антропология, религиозная тематика, этика и др. Но, как замечает о творчестве С. Л. Франка, В. В. Зеньковский, он обладал «исключительным даром ясного изложения,мысль его, всегда развиваемая систематически, покоряет столько же своей основательностью, сколько и удачными формулами, которые очень часто стоят длинных рассуждений». Кроме того, Франк обладает огромным литературным дарованием, что «делает его анализы и рассуждения прямо мастерскими». Но вместе с тем, рядом с этим «стоит и нисколько не уступает глубина его философского усмотрения - ум его синтетический, по существу, оплодотворяется 
той метафизикой всеединства, которую Франк развивает в своих произведениях, всегда оригинально и глубоко. По силе философского зрения Франка без колебания можно назвать самым выдающимся русским философом вообще - не только среди близких ему по идеям». [1. C.450] С этим высказыванием Зеньковского нельзя не согласиться, поэтому не случайно в последнее время творческое наследие Франка изучается широким кругом исследователей. Сюда можно отнести П. П. Гайденко, Л. Н. Столовича, В. Н. Ильина, М. А. Маслина, С. А. Левицкого и других [7].

Свою собственную философию Франк характеризует как «христианский реализм». Он признает божественную основу мира, религиозную ценность бытия, но в то же время подчеркивает «роковое» несовершенство его эмпирического состояния бытия и поэтому ограниченность возможностей человеческого совершенствования. Это его исходная позиция, с которой он подходит к решению всех других философских проблем, в том числе религиозных, правовых и нравственных. Среди этих проблем особое значение и актуальность в настоящее время приобретает проблема личности, ее прав и свобод [6].

Как и Н. Бердяев, С. Л. Франк исследует проблему личности, возвышения личности. Но ради истины подчеркнем, что в концепции Бердяева, личность онтологична, нравственность как таковая носит у него доисторический характер, т.е. создается Богом. У Франка же, исходя из «Рокового несовершенства эмпирического состояния бытия», личность должна совершенствовать себя самого в несовершенном обществе. Поэтому, по Франку, приходится признать, что условием развития общества является задача самосовершенствования личности и, через нее, и самого общества. И у С.Л.Франка, таким образом, личность первична, самоценна по отношению к обществу. В работе «Политика и идеи» он пишет: «В нашем философскополитическом мировоззрении мы исходим из идеи личности как носителя и творца духовных ценностей, осуществление которых в общественно-исторической жизни образует содержание культуры... Личность, подчеркивает Франк, - для нас священна сама по себе, в силу присущего нам морального сознания, которое гласит, что человек должен всегда рассматриваться как цель и никогда - как простое средство, и требует от нас уважения ко всякой человеческой личности как таковой». [3. - С.69] Таким образом, Франк вслед за Кантом отстаивает право личности на свободное развитие именно как носитель и творец духовных ценностей.
И хотя мир и Россия переживали не лучшие времена (статья «Политика и идеи» напечатана в декабре 1905 г.), когда в России происходили кровавые события - декабрьское вооруженное восстание рабочих, С.Франком в статье провозглашается непреходящая ценность личности: «И личность для нас, подчеркивает он, - священна, как живая и вечная лаборатория духовного творчества, как единственная на земле реальная точка, в которой и через которую действует божественный дух». [3. - С.69].

Таким образом, у Франка не общество носитель и средоточие божественного духа, а человек, личность и поэтому нет заботы выше, как забота о человеке, о его благе! А посему, рассуждает Франк, «нет блага, которое было бы благом само по себе, если оно не служит личности; нет священной цели, кроме цели служения свободе и развитию личности». [3. С.69].

И общество, и прежде всего, государство в своей деятельности должно исходить из идеи свободы личности, обеспечения ее неприкосновенности, и свободы, а поэтому государство не может быть неограниченным властителем над личностью. Оно должно быть ограничено вечными и ненарушаемыми правами, вытекающими из ее нравственного значения» мысль и совесть не могут находиться под властью людей - они подчинены лишь своему собственному верховному суду и лишь перед ним повинны отчетом». [3. С.69].

Провозглашая идеи свободы личности, С.Франк опирается на исторический опыт человечества, который свидетельствует о пагубности пути подавления личности. «Старая античная идея» полного поглощения личности государством, - рассуждает Франк, - растворения без остатков всех духовных сил и помышлений в механизме государственной власти», идея, следы которой, еще так сильны и в наших учреждениях, и в наших умах, - противоречит современному нравственному сознанию и должна быть отвергнута решительно и безусловно». [3. - С.70].

Какие же ценности «современного нравственного сознания» составляют его фундамент? Это ценности, провозглашенные Декларацией прав и свобод человека и гражданина. Об этом и пишет в своем памфлете «Политика и идеи» С.Л.Франк. В ту бурную, революционную эпоху эти идеи вновь оказываются востребованными. Это свобода совести и мысли, свобода слова, свобода собраний - суть неотъемлемые права личности, вытекающие из основного права личности на самоопределение и свободное развитие. И «Какова бы ни была форма власти, в чьих руках бы она ни находилась и как бы искренно она ни руководствовалась интересами народного блага, 
действительными потребностями большинства она не вправе приносить в жертву своей цели эти неотъемлемые права личности». [3. - С.70]. И далее Франк подчеркивает, что личность стоит выше государства, и никакое государство не может (не должно) смотреть на нее только как на свое орудие. А посему «всякая диктатура, от кого бы она ни исходила и какими бы соображениями ни руководствовалась, одинаково безнравственна и недопустима». [3. - С.70]. Здесь мы видим уже существенное отличие марксистского понимания этого вопроса, поскольку там разработано было учение о диктатуре пролетариата. Франк же, как видно из вышесказанного, выступает против всякой диктатуры, ибо, по Франку, «право должно служить обеспечению свободы, и всякий порядок, убивающий свободу, противоправен и беззаконен». [3. - С.70]

Следующее

положение,

которое рассматривает Франк в указанной статье это проблема равноправия человека, которая также не утратила своей актуальности и в настоящее время. Франк считает, что несмотря на их естественные различия, все люди в государстве равны, как человеческие личности. Они равноценны, т.к. в равной мере выступают как представители священного начала личности. И человек не может быть средством и орудием для другого человека и, следовательно, по Франку, они равны по своему моральному значению. И что очень важно, так это, то что это равенство требует для себя политического выражения в принципе демократии. Франк далее пишет, что в этом вопросе «недопустимы никакие сословные и национальные привилегии, никакие преимущества и отличия, юридически прикрепленные к отдельным избранным группам личностей в силу самого происхождения». [3. С.70]. И никакие «кремлевские пайки», никакие «мигалки» и крутые денежные оклады, и никакое самоуправство неприемлемо в демократическом обществе. Более того все люди, в силу их свойства как носителей духовного и общественного идеала, имеют право на равное участие в политическом творчестве, в образовании государственной власти. По мнению С.Франка, «власть может принадлежать только всему народу и всем его членам в одинаковой мере». [3. - С.70.]. И главное требование народовластия - всеобщее и равное избирательное право, ответственность власти перед народом. Чего в России, к сожалению, уже давно нет. И морально-политическим постулатом демократического движения должны стать, по Франку, свобода личности и равноценность, а следовательно, и равноправие отдельных личностей.

Но осуществление демократии должно происходить не только в политической, но и в области хозяйственных и социальных отношений. Человек как личность не может быть средством, орудием в руках другого человека, а отсюда, по Франку, и возникает «моральная недопустимость хозяйственной эксплуатации и социальных привилегий». [3. - С.71]. И далее, по Франку, идея социализма гораздо шире и глубже тех экономических и политических лозунгов, с которыми оно обычно отождествляется: лозунги освобождения личности и демократизации общества, по Франку, примененные к экономической жизни логически приводят к идее социализма, но точнее «ее образуют» [9].

Поэтому то истинная свобода, как и истинное равноправие, осуществимы лишь в обществе, «в котором народ сам так же управляет своей хозяйственной судьбой, как и судьбой политической». [3. - С.71]. И далее очень важная мысль, прозвучавшая у Франка, и которая очень важна для уяснения теории социализма как общественного строя уже в наши дни: «Диктатура пролетариата», экспроприация капиталистов, даже отмена частной собственности и обобществление орудий производства не исчерпывают собой основной идеи социализма и даже совсем не затрагивают ее». [3. - С.71]. Более того, все это - лишь частичные, частью односторонние, частью прямо неверные технические приемы осуществления социализма. Даже тогда, когда социализм понимается как коллективное хозяйствование народа или как известная заранее определенная организация производства, обмена и распределения, по Франку, «не может иметь принципиального морально-политического значения». [3. - С.71]. Ибо принципиально в социализме лишь перенесение идей свободы и равноправия личностей на экономическую и социальную область. И еще принципиально в этом вопросе требование отмены хозяйственной эксплуатации и социальных привилегий. И далее: «Социализм есть великая проблема наших дней, но для решения ее нужны не только практические, но и идейные усилия...» [3. - С.71]. Увы! Таких даже просто идейных усилий в улучшении духовной ситуации в России не произошли [8].

Теперь, экстрапалируя эту мысль Франка на сегодняшний момент жизни общества, можно констатировать, что тот советский социализм в СССР был технически осуществлен без решения главной его, сущностной стороны - со стороны решения проблемы истинной свободы и истинного равноправия каждого человека, каждой личности и ответственности общества за судьбу и благосостояние его членов, права личности, как члена солидарного целого. Поэтому необходимо «требовать от общества обеспечения себе условий свободной, разумной и 
достойной жизни - вот великий новый моральный принцип, который следует из социалистического учения [3. - С.72]. Этого требует и философское, морально-политическое понимание затрагиваемой проблемы. И так называемый, «реальный социализм» в СССР главной проблемы социализма не решил, отсюда все коллизии и трагизм первого опыта построения социалистического общества. К сожалению, в СССР был осуществлен другой принцип - первенство, главенство, диктат общества над личностью. Личность здесь просто винтик в общественном механизме. Произошло подавление личности вплоть до создания Гулага. Таким образом, предостережения русских философов начала XX века не были услышаны партией большевиков, а затем КПСС, отсюда и крах этого общества, отсюда и разрыв между научно-техническим и социальным прогрессом, которого, по-сути, нет.

В настоящее время проблему социальной свободы решают и именуют как либеральнодемократические идеи. Но основу этих идей все же должна составлять великая, хотя и старая, но неумирающая формула - свобода, равенство, братство, как обобщение основных моральных мотивов, руководящих политическим и социальным прогрессом.

Но идеи и идеалы нужны нам, по Франку, не только для того, чтобы знать как нужно действовать, но и для того, чтобы знать, какие пути к осуществлению задачи должны быть признаны допустимыми и целесообразными. Франк подчеркивает, что приемы всякой общественной и политической деятельности вытекают из самых основ морального, политического и социального миропонимания. Когда допустим и целесообразен прием насильственной борьбы, когда и как можно добиваться и удерживать в своих руках моральное влияние на общество и политическую власть над ним? Ответы на эти вопросы надо искать во вдумчивом, свободном от предвзятости обсуждении «...иначе, - подчеркивает С.Л.Франк, - мы рискуем, следуя за шаблонами и трафаретами, потерять из виду живую действительность и совершить ряд гибельнейших ошибок. А как мало теперь у нас думают обо всем этом!» [3. - С.73]. Как же прав Семен Людвигович Франк, как часто человечество совершает ошибки, т.е. теряет из виду эту самую «живую действительность»! И далее Франк подчеркивает, что «единственной основой всякого политического и социального порядка, как и единственным и последним двигателем всякого политического и социального прогресса... является общественное мнение, совокупность и равнодействующая господствующих в народе верований, стремлений и настроений». [3. - С.73]. И следовательно, для этого нужен определенный уровень культурного развития, нужен исторический опыт и политический навык, «чтобы убедиться ясно и непреложно в конечном всемогуществе общественного мнения, в бессилии всех попыток насильственного его подавления и в политической опасности высокомерного пренебрежения им». [3. - С.73]. И далее Франк сетует, что таких условий еще не хватает в России, а пишет он об этом в 1905! А в 2016 году в России по-прежнему этого не хватает. До сих пор в России существует пренебрежение к общественному мнению, т.к. социологическая наука у нас снова не в чести, а государственное принуждение в политике (например, использование в предвыборной компании административного ресурса) присутствует в полном объеме, манипулирование общественным мнением, подкуп голосов и другие приемы. Так что социальный прогресс, мягко говоря, не слишком заметен, а для обозначения социальной свободы теперь часто используется термин «достойная жизнь», предполагающий социальный комфорт личности в обществе. Но этого общество еще не достигло, ибо не может быть свободным, процветающим народ, если хотя бы один человек чувствует себя несвободным. Но пока таких обществ нет на Земле. А в России человек находится в условиях бесконечной борьбы за выживание и о гарантированном жизнеобеспечении гражданин России может только мечтать. Зато олигархи с чиновниками в погоне за личным обогащением утрачивают последний здравый смысл, не видя пагубности подобного безнравственного поведения, грозящему углублению пропасти между богатством наверху и нищетой внизу. Такое общество не является стабильным и может закончиться социальным взрывом и распадом общества. Кстати, об этом уже знал и писал еще Аристотель [10].

Последние выборы - есть, скорее всего, последняя попытка сделки между народом и властью в вопросе решения главных социальных вопросов не выживания, а обустроенности всего общества сверху донизу.

В решении этих насущных задач нужен какой-то очень важный ориентир, идеал, и этот идеал - идея социальной справедливости. Некоторым политикам эта идея как кость в горле. Так, известный политик современной России, доктор экономических наук В.В.Жириновский в своей публичной речи по телевидению заявил примерно следующее: «Справедливости никогда не было и сейчас нет и никогда не будет!» Чтобы на эти сентенции либеральному демократу ответил бы С.Л.Франк? Он сказал бы, что «демократическое движение должно быть и по 
существу является движением социалистическим - борьбой за социальную справедливость и социальную солидарность». А социалистическое движение только в том случае пустит крепкие корни в живой действительности, если оно поймет свое дело как широкую задачу культурной, политической и социальной реформы и примкнет к могучему потоку, стремящемуся к демократическому переустройству и перевоспитанию общества» [3. - C.76]. Так пусть и для этого горе-политика идеалы демократии и свободы и социальной справедливости будут путеводной звездой для действительно демократического преобразования России. Иначе грош им цена этим всем политикам, которые в своих речах, поступках и делах о справедливости и не помышляют! Добавим, что даже демократические принципы Конституции России без активного внедрения их в жизнь ничего не означают.

Учитывая исключительно трагический характер переживаемого периода российской истории (хотя этих периодов у нее было много!), знаем и понимаем, что всегда при этом рождается много зла и слепоты, лукавства и низости. Время таково, говорил в 1923 году С.Франк, и случается так, что «умные и живые люди склонны подлеть и отрекаться от всякого духовного содержания» и даже честные и духовно глубокие натуры «склонны глупеть и терять живое отношение к действительности». [4.- C.14]. Живое и творческое отношение к кризисному историческому времени дает нам право найти тот ориентир, который поможет устоять и выстоять и выйти на твердую дорогу жизни. И этот ориентир,- говорил Франк,- социальная справедливость. Может не устоять обыватель, но не мыслящая личность, которая сможет оценить ситуацию, стать, как говорил Ницше, по ту сторону добра и зла, преодолеть в себе «жалкое довольство».

Должно же наступить время «умного делания»! Прав ведь Платон, который говорил, что управлять государством должен тот, кто мудр! И Ницше прав: «Не вокруг творцов нового шума - вокруг творцов новых ценностей вращается мир!» И С.Л.Франк прав, который критикуя старую интеллигенцию России XIX в., говорит о возможном повороте новой интеллигенции «от непроизводительного, противокультурного нигилистического (бесплодного) морализма... перейти к творческому, созидающему культуру религиозному гуманизму».[5. - С.100].

Предвыборная кампания в России не за горами. А прошедшие выборы высветили глубокие недостатки всей выборной системы, способствующей широкой возможности фальсификации выборов. Предвыборная кампания высветила грубые нарушения Конституции РФ в деятельности властных структур, а также системный кризис власти, поэтому стабилизации общественной жизни эти обстоятельства способствовать не могут. Нужны эффективные меры по спасению ситуации, недопущения «оранжевой революции». Но нельзя допустить и консервации, застоя в решении насущных задач развития нашего общества, предания процессам экономического развития новых импульсов. Вызовы истории таковы - пора сдвинуть с мертвой точки развитие промышленности, сельского хозяйства, создание новых рабочих мест. Требуется новое отношение к созданию нормальных условий для работы и жизни населения страны, коренного преобразования властных структур, резкого сокращения госаппарата. Управление страной надо сделать эффективным. Во власть должны прийти профессионалы, люди компетентные и ответственные за свои дела. Коррупцию выжигать надо каленым железом! Надо срочно спасать культуру, науку, образование и здравоохранение нации. Выборы в Государственную думу страны нужно сделать такими, чтобы к власти пришли люди, готовые эффективно решать назревшие проблемы в интересах всего общества, а не отдельного зажиревшего клана. Этому нас учит наше русская философская мысль и ее ярчайший представитель - Семен Людвигович Франк. Ибо, как справедливо заметила П. П. Гайденко: «Творчество Франка принадлежит к лучшему, что было создано русской философией Серебряного века и отдать должное глубокому мыслителю - значит продолжить дело его жизни и попытаться внести свою посильную лепту в разрешение тех вечных вопросов, которые его волновали». [1. - С.300]

\section{References:}

1. Gaidenko PP (2001) Vladimir Soloviev and the philosophy of the Silver Age - Moscow, 2001.
2. Zenkovsky VV (1999) The history of Russian philosophy. In 2 vols, T. II of -. Moscow - 


\begin{tabular}{l|lrl|l|ll} 
& ISRA (India) & $=\mathbf{1 . 3 4 4}$ & SIS (USA) & $=\mathbf{0 . 9 1 2}$ & ICV (Poland) & $=\mathbf{6 . 6 3 0}$ \\
Impact Factor: & ISI (Dubai, UAE) $=\mathbf{0 . 8 2 9}$ & PUHL (Russia) $=\mathbf{0 . 1 7 9}$ & PIF (India) & $=\mathbf{1 . 9 4 0}$ \\
& GIF (Australia) & $\mathbf{0 . 5 6 4}$ & ESJI (KZ) & $=\mathbf{1 . 0 4 2}$ & IBI (India) & $=\mathbf{4 . 2 6 0}$ \\
& JIF & $\mathbf{1 . 5 0 0}$ & SJIF (Morocco) & $=\mathbf{2 . 0 3 1}$ & & \\
\hline
\end{tabular}

Rostov-on-Don. Publishing house "Phoenix", 1999, T. II

3. Frank SL (1990) Politics and Ideas / About "Polar Star" // Works., Publishing House of the "Truth", 1990.

4. Frank SL (1990) The collapse of idols // Cit., Publishing House of the "Truth", 1990.

5. Frank SL (1990) Ethics nihilism // Cit., Publishing House of the "Truth", 1990.

6. Berdyaev NA (1989) The Meaning of Creativity // Berdyaev's philosophy of freedom. The meaning of creativity. - Moscow. 1989.
7. (2016) Plato. State // Op. Anthology of world philosophy, Moscow.: "Thought", Section V.1 Teaching about society and the state., pp. 396406.

8. (1997) Nietzsche Antichrist. From the book "Beyond Good and Evil" - Minsk, 1997, pp.290-306.

9. (1993) The Constitution of the Russian Federation. - Moscow, 1993.

10. Vladimir Zhirinovsky (2011) Public speech in the telecast of the March 2011.

Available: (Accessed: 10.03.2016).

et al. 